\title{
Legal framework governing Short-Term Medical Missions
}

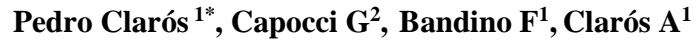 \\ ${ }^{1}$ Clarós Foundation, C/ Los Vergós 31, 08017 Barcelona, Spain. \\ ${ }^{2}$ Scholarship Clarós Foundation, Barcelona, Spain.
}

*Corresponding author: Pedro Clarós, Clarós Foundation, C/ Los Vergós 31, 08017 Barcelona, Spain.

Received date: March 22, 2021; Accepted date: March 29, 2021; Published date: April 05, 2021

Citation: Clarós P., Capocci G, Bandino F, Clarós A. (2021) Legal framework governing Short-Term Medical Missions. Clinical Medical Reviews and Reports. 3(4); DOI: 10.31579/2690-8794/072

Copyright: () 2021, Pedro Clarós, This is an open access article distributed under the Creative Commons Attribution License, which permits unrestricted use, distribution, and reproduction in any medium, provided the original work is properly cited.

\begin{abstract}
The presence and influence of Non-Governmental Organizations (NGOs) in the landscape of global health and development have dramatically increased over the past several decades.

Increasingly, Medical Practitioners in industrialized countries have become interested in global health issues, an interest that often takes the form of Short-Term international Medical Missions (STMMs).

His article will aim to help Medical Practitioners to have a synthetic overview of the legal framework governing medical volunteering in STMMs and give them some recommendations. The idea of this article started from the need to have an overview of the legal framework governing medical volunteering missions organized by the Claros's Foundation named "Foundation Clarós" (hereinafter also "FC"). To better understand who this article is addressed to, it is interesting to bring to your attention the concrete case from which this article was born. The following is a brief outline of what FC is all about. FC is a private, non-profit organization (NGO) whose aim is to provide medical care and alleviate the suffering of people in health and medical precarious situations.
\end{abstract}

Keywords: short term medical mission (STMMs), NGO, international law

\section{Background}

FC is very active in organizing humanitarian medical missions around the world. After the program started in 1992 in India, in the following years until 2021, many others humanitarian medical missions have been carried out in countries such as Cuba, Moldova, Romania, Jordan, Liberia, Ethiopia, Senegal, Cameroon, Gabon, Sudan, Kenya, Armenia, Democratic Republic of Congo, Cape Verde, Gambia, Uzbekistan or Burundi, always under the proposal of collaboration of local hospitals and government agencies (up to a total of 115 missions today). In many of these countries, the missions have been repeated regularly every year. For example, in Senegal 10 missions, in India 14 missions, etc...

FC has a network of over 50 volunteer health professionals, including ear, nose and throat surgeons, maxillofacial surgeons, specialists in facial plastic surgery, nurses, audiologists, anesthetists and other professionals from other surgical specialties, such as vascular surgery or ophthalmology. Most of them come from different cities in Spain, Portugal, Poland, Romania, France, the United States and other countries where FC humanitarian missions are carried out.

Each mission prepares a team of 8 to 10 people (surgeons, anesthetists, nurses, audiologists and medical coordinator.) with basic language skills and these missions last 7 to 10 days, which is what is called STMMI.
The local operating theatres are adapted so that two operations can be carried out at the same time in each of them, which means that each mission can be carried out for $80-100$ operations by mission.

The work that all these health professionals do is possible thanks to the support received from private individuals, private companies and bodies that collaborate and support the Foundation, both through financial contributions and through the donation of medical equipment.

During these 25 years that the FC has carried out its medical activity, it has been able to observe many faults by other NGOs regarding compliance with International Law. Precisely the reason for preparing articles on the prevalence of international law by medical NGOs has been his worrying thought.

\section{Introduction}

\section{Non-Governmental Organizations (NGOs)}

Non-Governmental Organizations (NGOs) are also called by various names across the world (i.e. third sector organizations, non-profit organizations, voluntary organizations, charitable organizations, community-based organizations, etc.) with slight modified scope and coverage.

There is no generally accepted definition and the term carries different connotations in different circumstances [1]. International law recognizes 
the existence of NGOs through several functional categories. Nevertheless, for legal scholars, there are some fundamental features [2]:

- The concept of a volunteering or not-for-profit entity in terms of grouping together individuals who are free and considered to be vested with rights with a view to achieving a common purpose for the benefit of others and not for the members alone;

- The humanitarian aims [3].

- The special legal framework it symbolizes, depending on national legislation;

- The relationship with public and private authorities both at the national and international level (with the State and its institutions, in particular);

- The reference to values involving both a voluntary commitment and the declared will to ensure that the work of the volunteering group is consistent with a civic approach geared, to a varying extent, to the "civil societies" of which NGOs form an essential part;

- The transnational nature of the work carried out, irrespective of the conditions and procedures that govern it

Further characteristics of NGOs may include the criteria to have an established headquarter and a democratic structure. NGOs remain essentially private legal entities, formed under and essentially governed by the national laws of the countries in which they are established. However, limited number of national laws even grants them specific recognition today within the wide non-for-profit world [4].

The importance of NGOs is gaining increasing recognition to fill gaps left by the failure of states across the developing world in meeting the needs of their citizens. In their role as service providers, NGOs offer a broad spectrum of services across multiple fields, ranging from livelihood interventions and health and education service to more specific areas, such as emergency response, democracy building, conflict resolution, human rights, finance, environmental management and policy analysis.

Over the years, NGOs have become increasingly transnational. In fact, many organizations that initially worked only in the domestic frame have gradually extended their activities beyond national borders or have started interacting with intergovernmental organizations.

Despite NGOs that operate in the transnational sphere are increasing, the status of NGOs in international law has not yet progressed and there is a lack of agreement on NGOs as subjects of international personality.

Now, while in many countries' domestic legislation for "private associations" serves as a basis for NGO identification and recognition, at the international level, international legal standards to define and regulate the perception of NGOs have not yet been established. [5]

At the present states have not yet recognized NGOs as having an international legal personality and, consequently, at international level, there are no regulations under international law governing the establishment, requirements, and the international legal status of NGOs.

While there are no regulations under international law governing the establishment, requirements, and the international legal status of NGOs, some progress in the codification of NGO personality has been made on a regional level.
The most meaningful achievement in this matter is the "European Convention on the recognition of the legal personality of INGOs", which provides for the general recognition of the legal personality of an NGO in any state that is party to the convention.

The Convention is limited to international NGOs, defined by an "aim of international utility" and operation in at least two states. NGOs must have been established under the internal law of one of the State's party to the convention and must have their statutory office and central headquarters in the territory of one of the state parties as well.

Concerning the NGOs legal status, the Convention establishes an essential point: "every INGO carries with it its identity and its status without having to request new recognition from the various countries on its activities." [6]. Does this deal with all the problems as such? Far from it. Indeed, is still not a convention that enables NGOs to have an international personality.

To sum up, in general NGOs are obliged to accept the national legislation of the state in which they have been established and where they are based. Recognition, rights, and duties depend on the respective national conditions. Because of these differences in national laws, issues arise for NGOs in the international sphere. For example, difficulties arise when the activity of an NGO transcends the borders of its state of origin. An internationally operating NGO with branches in several states would fall under different national systems of law.

\section{Non-Governmental Organizations in health sector}

For purposes of this paper, we outline the significant role played by NGOs in health system. Many of these focuses on deliver provision of healthcare services; others operate public health program, provide technical assistance, or focus on health research.

The presence and influence of Non-Governmental Organizations in the realm of global health and development have dramatically increased over the past several decades. They operate projects in low and middle-income countries throughout the world. Their number has grown twenty-fold since 1951 and increasingly donors prefer to channel aid to and through NGOs rather than directly to foreign governments [7]. In 2006, transfers of official development aid to NGOs totaled more than \$2 billion (US dollars) according to OECD statistic; services, such as education and health care, historically managed and implemented by the public sector, are increasingly provided by NGOs [8].

Increasing numbers of NGOs have dispatched groups of volunteer health professionals in humanitarian medical aid missions in resource-poor countries where obtaining medical services is difficult for most patients.

The number of health professionals from high-income countries on medical missions to provide care in low-and-middle-income countries is growing globally also due to the globalization which has led to a new sense of the individual as a citizen of the world. It is reflected in health care by a growing awareness of public health as a global rather than a national issue and it is, at least, partially responsible for the increasing numbers of health care professionals who volunteer for medical service missions.

Medical missions, defined as "grass root, direct, medical service aid from wealthier countries to low and middle income countries [9]", are an important part of how health care is provided by NGOs all over the word. Indeed, many Clinicians participate in medical missions through nongovernmental organizations, including charities and faith-based 
organizations, although the activities of such organizations are less frequently described in the academic literature.

Such medical trips focus on assessing the medical needs of the population encountered and providing medical opinions/consultations, medications and surgeries. Such missions are necessary due to a lack of sustainability principles and limited capacity building opportunities and institutional development in developing nations, and have led to increased volunteerism of highly skilled Medical Practitioners collaborating with Medical Professionals based in the local communities where these missions occur.

The volunteer organizations that send international health volunteers can unevenly be divided into:

- secular medical NGOs, such as Médecins Sans Frontières, which often identify themselves as humanitarian organizations;

- development NGOs, often rooted in Christian missionary organizations, but including also a number of secular NGOs that are mainly involved in long-term development aid;

- Volunteer organizations, which define sending volunteers as their core mission [10].

\section{Short-Term Medical Missions (STMMs)}

Medical aid trips are categorized into short- and long-term missions. Over the years, as many long-term healthcare operations have been replaced by sector-wide approaches, there has been a shift in focus from long-term overseas assignments to short-term medical missions (STMMs) [11].

STMMs refers to an activity wherein Physicians and other Medical Workers from higher income countries travel to provide direct care to people in lower and middle income countries without compensation for a period from days to a few weeks. Such "missions" are planned, and represent an unsanctioned, grass-roots, and highly direct expression of trans-national aid. These medical excursions are differentiated from ad hoc responses to domestic or external disasters, full-time relief practice such as Médecins Sans Frontières (MSF), military or other governmental relief expeditions and officially sanctioned medical student or residency training programs [7].

There are three types of STMMs: emergency, surgical, and mobile services. Emergency services provide post-disaster medical relief care anywhere in the world. Surgical services provide dental and surgical aid in regions where such services are generally unavailable. Mobile services provide clinics in outlying villages where medical care is either lacking or inadequate [13].

\section{Discussion}

\section{Future aspects}

The future aspects that derive from this study and of all the others which are carried out, should always consider the clinical and surgical features in which the STMMs should be based on. It has to be clear enough that actions the NGOs use when conducting a humanitarian mission, have to be focused to help out the needed community. It will always be avoided that the STMMs can be used as medical safari trips where young doctors practice and improve their skills.

\section{Ethical issues in STMMs}

It has been argued that much of international medical volunteering is done for the wrong reasons, in that local people serve as a means to meet volunteers' needs, or for the right reasons but ignorance and illpreparedness harm the intended beneficiaries, often without volunteers' grasp of the damage caused. The literature on ethical concerns in medical volunteering has grown tremendously over the last years highlighting the need for appropriate guidelines. [14]

Throughout the literature, examples reveal a disregard of ethical codes or an application of double standards [15] based on the fact that local patients have little or no choice but to accept the offered care. Therefore, a widespread view is that any care is better than nothing [16], even if it means dispensing useless tablets just because patients have walked far to the clinic - giving the volunteer a chance to look benevolent. The acceptance of lower standards in underprivileged settings (different countries - different rules) also absolve, of course, a volunteer of taking full responsibility for the delivered care [17]. What many volunteers do not realize is that they may work outside local legal governance and regulations [18], especially if they are working independently from an established organization [19].

\section{Legal issues in STMMs - Risk of liability}

Despite the increasing popularity of the STMMs, there are many legal issues surrounding medical volunteerism missions that remain unclear [20] due to the paucity in literature on this matter.

Given the difficult circumstances in which Medical Volunteer may operate, it is important to assess the legal issues surrounding medical volunteering [20].

The risk of civil liability for harm to patients is one of the most contentious legal issues. Health Professionals who volunteer may face civil liability for negligence or intentional torts committed while performing their duties.

There are several reasons for which Volunteer healthcare Workers may have an increased risk for committing medical errors, including unavailability of or inadequate health records, laboratory testing, emergency services, examination facilities and referral services for adequate follow-up. Language barriers and limited time with the patient further inhibits the ability to perform a proper medical assessment. Furthermore, the visiting provider is most likely unfamiliar with the standard of practice in the host country while, similarly, the host country providers may be unfamiliar with medications and treatments provided by Volunteer healthcare Workers.

Limited time on location is one of the intrinsic features of STMMs, and this leads to considerable consequences [21]. This time is usually filled with as many surgeries and other treatments as possible to make the mission worthwhile. While volunteers can report how many patients they have seen in which timeframe, they have no way of knowing if the treatment was successful. Unless a condition can be treated completely in one visit, volunteers are unable to provide continuity of care, await lab results, deal with any complications, etc., and, overall, cannot be held accountable for their actions.

It is important to be noted that the way liability arises may vary across jurisdictions and the approach to legal protection of volunteers is nonuniform amongst various jurisdictions.

In Countries, adopting the civil law system liability is likely to arise out of legislation, whereas in other Countries liability may arise out of statutes and/or the common law concept of tort. 
Generally, in civil law Countries liability in instances of Physicians should fall under the scope of the civil law (contracts, torts) liability. In some jurisdiction, the NGOs may be held liable because the volunteer acts on behalf of the organization. In particular, in many common law systems, a claim may be made for negligence on the part of the organization which has failed to comply with a legal duty of care towards its Staff.

Many common law jurisdictions also have exemptions from volunteer liability for acts carried out in "good faith". Under the Australian Civil Liability Act of 2002 "A volunteer incurs no personal liability for an act of omission done or made in good faith and without recklessness in the course of carrying out community work for a community organization, including governmental and non-governmental organizations".

In the USA, the Federal Volunteer Protection Act of 1997 aims to promote volunteerism by limiting, and in many cases completely eliminating, a volunteer's risk of tort liability when acting for non-profit organizations or government entities. No volunteer of a nonprofit organization or governmental entity shall be liable for harm caused by an act or omission of the volunteer on behalf of the organization or entity.

Moreover, some federal and state laws provide protection from civil liability through immunity or indemnification. These protections may be limited to individuals responding under the auspices of an organization. Good Samaritan statutes may provide limited protection from civil liability; however, whether protection exists and the level to which it provides protection will be dependent on the state in which the action occurred.

Now, a question arises: there is a real risk of liability for Physicians in STMMs? Our answer is that, probably, there is not because Developing Countries may not have the luxury of worrying about medical malpractice. These countries may rightly dedicate more time and attention to addressing public health crises rather than focusing on medical negligence [22-23].

Patients in developing countries are less "equipped" than patients in the developed world to issue and report medical negligence; indeed, patients do not have the requisite literacy, education, and financial resources.

Another obstacle is the fact that, in the majority of the developing Countries, the body of law is underdeveloped from a personal injuries and medical malpractice point of view; moreover, patients in developing countries often have problems with access to justice.

These jurisdictions frequently struggle with massive case backlogs, weak judicial institutions, inadequate legal infrastructure, corruption, etc.; due to these several reasons, parties in developing countries often prefer to settle their disputes informally [24].

Although malpractice lawsuits are rare in Developing Countries, under some legal systems, organizations have to subscribe insurance policies covering their volunteers; such insurance obligations often are to be found in laws on employer's liability and may also apply to any volunteers. Additionally, organizations may be responsible for ensuring that individuals carrying out specific activities have their own insurance policy [25].

\section{NGOs vs governmental and non-governmental or profitable vs non profitable organizations.}

Both organizations have a very relevant mission in the current world. In any case, there is a clear behavior between them due to the freedom in action of the NGOs in comparison with the governmental organizations, as they do not have the obligation of following the conditions enforced by the proper Government. The same occurs with the organizations whose objective is to obtain benefits such as exchange of their action, while the second one, acts without any exchange.

\section{Medical malpractice insurance}

Most traditional professional liability insurance policies do not cover actions abroad. Such coverage is only available in the form of specialized policies. These policies have limitations in the form of high premiums, limited coverage and lack of availability in certain locations [25].

Most organizations do not provide medical malpractice coverage, and some go so far as to state that coverage is not necessary because the likelihood of a lawsuit is negligible [26, 27].

Many non-profit organizations that send physicians abroad have volunteers sign a waiver stating that no medical liability insurance is available within the program [28].

\section{Conclusions}

The legal frameworks governing medical volunteering are unclear and vary from one jurisdiction to another. Both Doctors and NGOs involved in medical volunteering in developing countries need to consider the legal ramifications of their work.

Each Physician must be informed about the rights, obligations, and specifics of the volunteer engagement before it begins. The disclosure requirement is important, as it ensures:

- That the volunteer is engaged in activities he/she expected or that motivated the volunteering;

- That volunteers understand their rights and the circumstances that define them;

- That they are informed of any possible danger that might arise from the activity.

Volunteers and organizations should regulate the specifics of their relationship and volunteer's rights and obligations through formal agreements.

\section{References}

1. Willetts P. (2002) What is a Non-Governmental Organization? Research Project on Civil Society Networks in Global Governance.

2. Ryfman P. (2007) Non-governmental organizations: an indispensable player of humanitarian aid. International Review of Red Cross. (89) 865:21-46

3. European Convention on the Recognition of the Legal Personality of International of Non-Governmental Organizations Strasbourg, 24/04/1986.

4. Doucin M. (ed.), (2007) Le Guide de la liberté associative dans le monde: 183 législations analysées, 2nd ed. La documentation Française, Paris.

5. Martens K. (2003) Examining the (Non-) Status of NGOs in International Law. Ind. J. Global Legal Stud. 10 (2):1-24.

6. Merle M. (1995) Un imbroglio juridique. Le "Status" des ONGs entre le droit international et les droits nationales. Transnationales Associations. (5): 266-272.

7. Yearbook of International Organizations Union of International Associations.

8. Mercer C. (2002) NGOs, civil society and democratization: a critical review of the literature. Prog Dev Stud.; Epstein G, Gang 
I. “Good Governance and Good Aid Allocation, 2008, Rutgers University-Department of Economics

9. Caldron P, Impens A, Pavlova M, Groot W. (2016) Economic assessment of US physician participation in short-term medical missions. Global Health. 12(1):45

10. Laleman G, Kegels G, Marcha B1, D.Van der Roost, Bogaert I, Van Damme W. (2007) The contribution of international health volunteers to the health workforce in sub-Saharan Africa. Hum Resour Health. 5: 19.

11. Bajkiewicz C. (2009) Evaluating short-term missions: how can we improve? J Christ Nurs. 26(2):110-4.

12. Roche, S.D., Ketheeswaran, P. \& Wirtz, V.J. (2017) International short-term medical missions: a systematic review of recommended practices. Int J Public Health. 62(1):31-42.

13. Dupuis CC. (2004) Humanitarian missions in the third world: a polite dissent. Plast. Reconstr. Surg. 113(1):433-5

14. Bauer I. (2017) More harm than good? The questionable ethics of medical volunteering and international student placements. Tropical Diseases, Travel Medicine and Vaccines Trop Dis Travel Med Vaccines. 3(5):12.

15. Langowski M., Iltis A. (2011) Global Health Needs and the Short-Term Medical Volunteer: Ethical Considerations. HEC Forum. 23:71-8.

16. Wall A. (2011) The context of ethical problems in medical volunteer work. HEC Forum. 23: 79-90.

17. Berry N. (2014) Did we do good? NGOs, conflicts of interest and the evaluation of short-term medical missions in Sololá. Guatemala Soc Sci Med. 120:344-51.

18. Elnawawy O, Lee A, Pohl G. (2014) Making short-term international medical volunteer placements work: a qualitative study. Br J Gen Pract. 64(623): e329-35.

19. Bishop R, Litch J. (2000) Medical tourism can do harm. BMJ. 320(7240):1017.

20. Elgafi S. (2014) Medical liability in humanitarian missions. Journal of Humanitarian Assistance.

21. Cortez N. (2012) Medical Malpractice Model For Developing Countries?

22. Lasker JN, Aldrink M, Balasubramaniam R, et al. (2018) Guidelines for responsible short-term global health activities: developing common principles. Global Health. 14(1):18.

23. Cranston R. (1997) Access to Justice in South and South-East Asia, Good government and law: legal and institutional reform in developing countries 233 .

24. Legal issues related to volunteering Toolkit for National Societies International Federation of Red Cross and Red Crescent Societies, Geneva 2011.

25. Uejima T. (2011) Medical Missions and Medical Malpractice: the current state of Medical Malpractice Overseas. American Society of Anesthesiologists. ASA. 75 (2):22-24.

26. Legal Issues Facing Humanitarian Medical Missions Abroad. The 9th International RAMA-RADA-RASA Medical and Scientific Conference November 9-11, 2012 Philadelphia, Pennsylvania, Marchildon G.P.

27. McIntosh T., Forest P G. (2004) The Fiscal Sustainability of Health Care in Canada. Romanow Papers, Vol 1. Pp. 118. University of Toronto Press. Advancing Knowledge.

28. Marcus D. (2010) Are you protected from liability when volunteering at home, abroad? AAP News. 31:1.18. 